\title{
A Method of Secret Coding technique on Two Star Graphs
}

\author{
G. Uma Maheswari \\ Department of Mathematics \\ Dhanalakshmi Srinivasan \\ College of Engineering \\ Chennai
}

\author{
J. Arthy \\ Department of Mathematics \\ Bharath Institution of Higher \\ Education and Research \\ Chennai
}

\author{
Suzan Jabbar Obaiys \\ School of Mathematics and \\ Computer Science \\ Heriot-watt University \\ Malaysia
}

\begin{abstract}
Super Mean Labeling is one the interesting topic in graph theory. There also are search that has proved that the super mean labeling is not possible forth the star graphs. In this paper, we generalized the concept of super mean labeling on two star graphs and develop a technique of coding a secret messages using two star graph through super mean labeling. Two types of coding, picture and matrix coding have been illustrated by using different types of numbering of alphabets and algorithm is established.
\end{abstract}

\section{General Terms}

Coding Method, Matrix coding, Algorithms

\section{Keywords}

OFEF, EFOF, OFEB, EBOF, super mean labeling, and star graphs

\section{INTRODUCTION}

Graph theory is one such branch of Mathematics, which has established itself as an important mathematical tool due to its scientific and engineering applications in many areas like computing, social and natural sciences such as coding theory, cryptography, matrix theory, chemistry and to mention a few. Hence Graph theory has been accorded a place of pride in Applied Mathematics. A Graph Labeling is an assignment of integers to the vertices or edges, or both, subject to certain conditions. In cryptology, a code is a method used to encrypt a message that operates at the level of meaning, that is words or phrases are converted into something else. This research work involves the text message is converted into matrix and picture coding. The U.S national security agency defined a code as a substitution crypto system in which the plain text elements are primarily words, phrases or sentences, the converted code equivalents called code groups typically consists of letters or digits or both. In this research article the coded message consists of Greek letters.

\section{LITERATURE REVIEW}

Graph theory is too generous and prolific offering innumerable concepts with applications galore. After a search for a suitable topic for research, the concept of graph labeling was selected by the researchers [1-3]. The concept of super mean labeling was introduced and studied by D. Ramya, et. al. [4-7]. The super meanness property of the subdivision of the H-graph and slanting ladder was studied by R.Vasuki and A. Nagarajan [8] and super meanness of sub division graph of $K 1,3$, some caterpillars and some duplicate graphs were studied by R. Vasuki and A. Nagarajan [9-12]. The communication becomes very much limited between the sender and the receiver and not to be understood by others. Coding through a two and three star graph with super mean labeling is structured by Uma Maheswari, et. al. [13], and coding with Fibonacci web is established by Uma Maheswari, et. at. [14] Motivated by these work, we worked on three star graphs by applying super mean labeling and GMJ (Graph Message Jumbled) coding method and hence this paper.

\section{DEFENITIONS}

\section{Definition 2.1}

Let $\mathrm{G}$ be a $(p, q)$ graph and

$\mathrm{f}: \mathrm{V}(\mathrm{G}) \rightarrow\{1,2,3, \ldots, \mathrm{p}+\mathrm{q}\}$ be an injection. For each edge $e=u v$, let $f^{*}(e)=\frac{f(u)+f(v)}{2}$ if $f(u)+f(v)$ is even and $\mathrm{f}^{*}(\mathrm{e})=\frac{\mathrm{f}(\mathrm{u})+\mathrm{f}(\mathrm{v})+1}{2}$ if $\mathrm{f}(\mathrm{u})+\mathrm{f}(\mathrm{v})$ is odd. Then $\mathrm{f}$ is called super mean labeling if

$$
\mathrm{f}(\mathrm{V}) \cup\left\{\mathrm{f}^{*}(\mathrm{e}): \mathrm{e} \in \mathrm{E}(\mathrm{G})\right\}=\{1,2,3, \ldots, \mathrm{p}+\mathrm{q}\} .
$$

A graph that admits super mean labeling is called a super mean graph.

\section{Definitions 2.2.}

The two star graph is the disjoint union of two one star graphs $K_{1, m}$ and $K_{1, n}$ and is denoted as $K_{1, m} \cup K_{1, n}$.

Definitions 2.3.

The original intelligible message is known as Plain Text.

Definitions 2.4.

The transformed message is known as cipher Text.

Definitions 2.5.

An Algorithm for transforming an intelligible message into one that is unintelligible by transposition and substitution methods is known as cipher.

\section{Definitions 2.6.}

A Caesar cipher shifts the alphabet and is therefore called a shift cipher. Each letter is replaced by the letter three positions further down the alphabet. Caesar used a key 3 for his communication and it is known as Caesar Cipher or Shift Cipher.

\section{A RULE FOR SUPER MEAN}

\section{LABELING ON TWO STAR GRAPH}

1. Some observations on super mean labeling of $K_{1, m} \cup K_{1, n}, m \leq n$ are listed. Here $p$ and $q$ represent the number of vertices and edges, 
$p=2+m+n, q=m+n, p+q=2+2 m+2 n$.

The numbers from 1 to $2+2 m+2 n$ must be assigned to the top vertices and the pendant vertices and in the process, the edge values get allotted. Repetition is not permitted. Here $f(u), f(v), f\left(u_{i}\right)$ and $f\left(v_{i}\right)$ are the numbers assigned to the top vertices and the pendant vertices of the first and the second star respectively. The rule for getting the edge values is $\frac{\mathrm{f}(\mathrm{u})+\mathrm{f}\left(\mathrm{u}_{\mathrm{i}}\right)}{2}$ or $\frac{\mathrm{f}(\mathrm{u})+\mathrm{f}\left(\mathrm{u}_{\mathrm{i}}\right)+1}{2}$ where the edge connects $u$ and $u_{i}$.

Note that the edge value can be the actual or adjusted mean.

The average of the largest and the previous number is $\frac{(2+2 m+2 n)+(2+2 m+2 n-1)}{2}=2+2 m+2 n$.

As repetition is not allowed this combination is not considered. Hence neither the edge value nor the pendant vertices can exceed $2+2 m+2 n$. Hence it becomes possible to label a two star $K_{1, m} \cup K_{1, n}$ through super mean labeling for all values of $m$ and $n$ without omitting any number between 1 to $(p+q)$

2. If $\left(f(u)\right.$ and $\left.f\left(u_{i}\right)\right)$ or $\left(f(v)\right.$ and $\left.f\left(v_{i}\right)\right)$ are both odd or both even, then the edge value is the actual mean. If they are not alike then the edge value assumes the adjusted mean.

3. When $f(u)$ is odd and if $f\left(u_{i}\right)=2 s, f\left(u_{i+1}\right)=2 s+1$, they lead to same edge value and hence to be avoided that is $\frac{1+6}{2}$ and $\frac{1+7}{2}$ have the same edge value 4 when $f(u)=1$. When $f\left(u_{i}\right)=2 s+1$ and $f\left(u_{i+1}\right)=2 s+2$, they give different edge values and hence can be assigned. That is, $\frac{1+7}{2}=4$ and $\frac{1+8}{2}=5$ give different edge values. Also when $f(u)$ is even the situation is reversed. These to be noted while labeling the numbers to the pendant vertices.

Step 1: Take 1 and $p+q$ as $f(u)$ and $f(v)$ respectively. $f\left(u_{i}\right) \neq 2$, for the edge value becomes 2 but $f\left(v_{i}\right)=2$ is permitted.

Step 2: If $f\left(u_{1}\right)=3$, then $f\left(v_{1}\right)=4$ and if $f\left(u_{1}\right)=5$, then $f\left(v_{1}\right)=2$. That is, assign a value to $u_{1}$ and assign the next possible least integer to $v_{1}$ of the second star. Hence, $u_{2}$ and $v_{2}$ are labeled proceeding in the same manner. Once or twice we may have to continue with assigning to $u_{i}$ 's successively in order to avoid any repetition. This procedure makes labeling a two star graph easy using super mean labeling.

\section{Coding method}

There are different types of codes and ciphers. A code where a symbol, picture or group of letters represents a specific alphabetical letter or word. A cipher is where a message is made by substituting one symbol for letter here we used Greek letters for coding. The Caesar cipher is a shift cipher and is a substitution cipher where letters are replaced with letter or symbol with a fixed shift in the alphabet. The original intelligible message is known as plain text and the transformed message is known as cipher text.

By assigning numbers to the 26 alphabets of English in a different manner, choosing a suitable labeled graph with a given clue mathematical or non-mathematical, finding the number in the graph for each letter of each word of the given message and presenting the letter codes in a unique way in some form, writing it as a horizontal string or in any other way and creating a picture with the codes after shuffling the order of the letters in order to increase the secrecy of the coded message is named as GMJ coding method by [15].

The military slang is a set of colloquial terms which are unique to or which originated with personal and is often used to reinforce or reflect (usually friendly and humorous) interservice rivalries. The following illustration shows how the Military slang message (plain text) is transformed to matrix form (cipher text).

\section{Illustration 1:}

1) Message : keep up with the ins and outs of military life

2) Clue: Double the twinkling twins joining with single and abundance walking together

3) (Twinkling represents star, double the twins represents four, joining with one gives $4+1=5$ implies two star with 5 and abundance is 8 therefore it is two star graph )

4) Graph : The three star graph $G=K_{1,5} \cup K_{1,8}$,

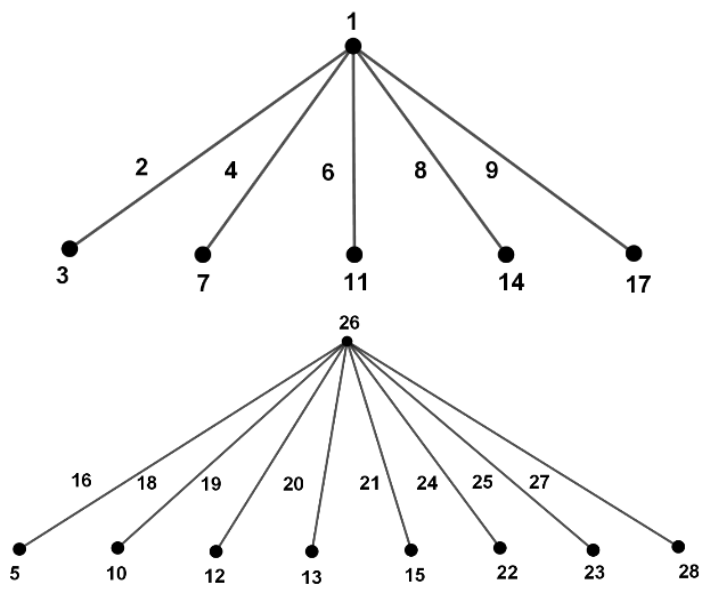

Fig 1: $K_{1,5} \cup K_{1,8}$

\section{5) Numbering of Alphabets: EFOF}

The number 1 to 13 are allotted to the even positioned alphabets moving forward from $\mathrm{B}$ to $\mathrm{D}$ to $\mathrm{F}$ and so on. And the numbers 14 to 26 are allotted to the odd positioned alphabets moving forward starting from $\mathrm{A}$ to $\mathrm{c}$ to $\mathrm{E}$ and so on. This method is named as EFOF (evens forward, odd forward)

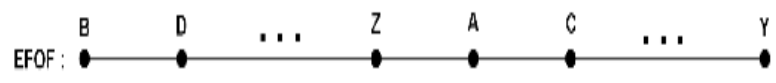

We express the numbering of alphabets in terms of a functions for encoding. For even positioned alphabets the functions is given by,

$g(2 k+2)=k+1$ for $k=0,1, \ldots, 12$ 
For odd positioned the function $\mathrm{g}$ us given by

$$
g(2 k-1)=(13+k) \text { for } k=1,2, \ldots, 13
$$

For decoding we reverse the process.

\section{6) Coding a letter:}

Corresponding to the letter in the message, the number is taken and it is located in graph. The Greek letters $\alpha$ and $\beta$ are used to refer to the first and second star respectively. $T, E_{i}$ and $V_{i}$ denote the top vertex, the $i^{\text {th }}$ pendant vertex and the $i^{\text {th }}$ edge value in order. For example $\alpha\left(P_{i}\right)$ denotes the number assigned to the $i^{\text {th }}$ pendant vertex of the first star.

7) Coding : (word wise)

$$
\begin{aligned}
& \text { Keep - } \beta\left(\mathrm{E}_{3}\right) \beta\left(\mathrm{E}_{1}\right) \beta\left(\mathrm{E}_{1}\right) \alpha\left(\mathrm{E}_{4}\right) \\
& \text { up - } \beta\left(\mathrm{E}_{6}\right) \alpha\left(\mathrm{E}_{4}\right) \\
& \text { with }-\beta\left(\mathrm{E}_{7}\right) \beta\left(\mathrm{E}_{2}\right) \beta\left(\mathrm{V}_{2}\right) \alpha\left(\mathrm{E}_{2}\right) \\
& \text { ins }-\beta\left(\mathrm{E}_{2}\right) \alpha\left(\mathrm{V}_{2}\right) \beta\left(\mathrm{V}_{6}\right) \\
& \text { and - } \alpha\left(\mathrm{V}_{4}\right) \alpha\left(\mathrm{V}_{2}\right) \alpha\left(\mathrm{E}_{1}\right) \\
& \text { outs - } \beta\left(\mathrm{E}_{5}\right) \beta\left(\mathrm{E}_{6}\right) \beta\left(\mathrm{V}_{2}\right) \beta\left(\mathrm{V}_{6}\right) \\
& \text { of - } \beta\left(\mathrm{E}_{5}\right) \alpha\left(\mathrm{V}_{1}\right) \\
& \text { military }-\beta\left(\mathrm{E}_{4}\right) \beta\left(\mathrm{E}_{2}\right) \alpha\left(\mathrm{E}_{3}\right) \beta\left(\mathrm{E}_{2}\right) \\
& \qquad \beta\left(\mathrm{V}_{2}\right) \alpha\left(\mathrm{V}_{4}\right) \alpha\left(\mathrm{E}_{5}\right) \beta(\mathrm{T}) \\
& \text { life - } \alpha\left(\mathrm{E}_{3}\right) \beta\left(\mathrm{E}_{2}\right) \alpha\left(\mathrm{V}_{1}\right) \beta\left(\mathrm{E}_{1}\right)
\end{aligned}
$$

\section{8) Presenting the letter codes:}

After finding the letter codes representing it as in horizontal string by inserting $(1,1)$ it denotes space between the two words. The letter codes are shuffled and by omitting the representations of the first star and the second star in order to increase the secrecy and presenting in matrix coding.

\section{9) Horizontal String:}

$$
\begin{aligned}
& \beta\left(\mathrm{E}_{3}\right) \beta\left(\mathrm{E}_{1}\right) \beta\left(\mathrm{E}_{1}\right) \alpha\left(\mathrm{E}_{4}\right)(1,1) \\
& \beta\left(\mathrm{E}_{6}\right) \alpha\left(\mathrm{E}_{4}\right)(1,1) \beta\left(\mathrm{E}_{7}\right) \beta\left(\mathrm{E}_{2}\right) \beta\left(\mathrm{V}_{2}\right) \\
& \alpha\left(\mathrm{E}_{2}\right)(1,1) \beta\left(\mathrm{E}_{2}\right) \alpha\left(\mathrm{V}_{2}\right) \beta\left(\mathrm{V}_{6}\right)(1,1) \\
& \alpha\left(\mathrm{V}_{4}\right) \alpha\left(\mathrm{V}_{2}\right) \alpha\left(\mathrm{E}_{1}\right)(1,1) \beta\left(\mathrm{E}_{5}\right) \beta\left(\mathrm{E}_{6}\right) \\
& \beta\left(\mathrm{V}_{2}\right) \beta\left(\mathrm{V}_{6}\right)(1,1) \beta\left(\mathrm{E}_{5}\right) \alpha\left(\mathrm{V}_{1}\right)(1,1) \\
& \beta\left(\mathrm{E}_{4}\right) \beta\left(\mathrm{E}_{2}\right) \alpha\left(\mathrm{E}_{3}\right) \beta\left(\mathrm{E}_{2}\right) \beta\left(\mathrm{V}_{2}\right) \\
& \alpha\left(\mathrm{V}_{4}\right) \alpha\left(\mathrm{E}_{5}\right) \beta(\mathrm{T})(1,1) \alpha\left(\mathrm{E}_{3}\right) \beta\left(\mathrm{E}_{2}\right) \\
& \alpha\left(\mathrm{V}_{1}\right) \beta\left(\mathrm{E}_{1}\right)
\end{aligned}
$$

10) Matrix Coding:

$$
\left(\begin{array}{llll}
E_{3} & E_{2} & V_{1} & E_{1} \\
V_{4} & E_{5} & T & (1,1) \\
E_{2} & E_{3} & E_{2} & V_{2} \\
E_{5} & V_{1} & (1,1) & E_{4} \\
E_{6} & V_{2} & V_{6} & (1,1) \\
V_{2} & E_{1} & (1,1) & E_{5} \\
V_{2} & V_{6} & (1,1) & V_{4} \\
V_{2} & E_{2} & (1,1) & E_{2} \\
E_{4} & (1,1) & E_{7} & E_{2} \\
E_{1} & E_{4} & (1,1) & E_{6} \\
E_{3} & E_{1} & (O, 0) & (O, O)
\end{array}\right)
$$

The following message is common military slang the word zero dark thirty represents really early in the morning.

\section{Illustration 2:}

1. Message: Meet the head at zero dark thirty.

2. Clue: A special prime twinkling perfect one. (Special Prime -2, it is the only even number which is prime, twinkling-referring to a Star. So, a two Star understood. First perfect number is 6 , therefore, the required graph is $K_{1,6} \cup K_{1,6}$

3. Graph: The two star graph $G=K_{1,6} \cup K_{1,6}$.
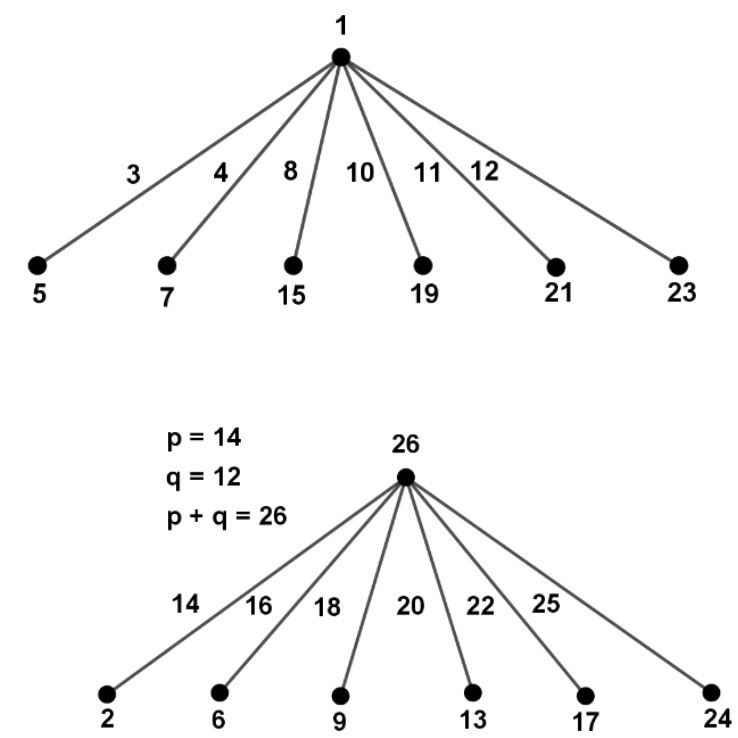

Fig 2: $K_{1,6} \cup K_{1,6}$

4. Numbering of alphabets: OFEF

The numbers 1 to 13 are allotted to the odd positioned alphabets moving forward from $A$ to $C$ to $E$ and so on. And the numbers 14 to 26 are allotted to the even positioned alphabets moving forward starting from $B$ to $D$ to $F$ and so on. This method is named as OFEF (Odds forward, Evens forward). 


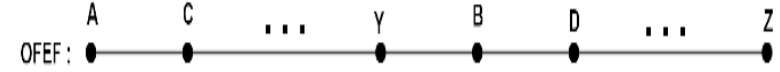

We express the numbering of alphabets in terms of a functions for encoding. For even positioned alphabets the functions is given by,

$g(2 k)=13+k$ for $k=1,2,3 \ldots, 13$.

For odd positioned the function $\mathrm{g}$ us given by

$g(2 k+1)=k+1$ for $k=0,1, \ldots, 12$ for decoding we reverse the process.

\section{Coding a letter:}

Coding and presenting the letter codes are followed by previous illustration.

6. Coding: (word wise)

$$
\begin{aligned}
& \text { Meet - } \alpha\left(\mathrm{V}_{2}\right) \alpha\left(\mathrm{E}_{1}\right) \alpha\left(\mathrm{E}_{1}\right) \alpha\left(\mathrm{V}_{6}\right) \\
& \text { the }-\alpha\left(\mathrm{V}_{6}\right) \beta\left(\mathrm{V}_{5}\right) \alpha\left(\mathrm{E}_{1}\right) \\
& \text { head }-\beta\left(\mathrm{V}_{5}\right) \alpha\left(\mathrm{E}_{1}\right) \alpha(\mathrm{T}) \alpha\left(\mathrm{V}_{3}\right) \\
& \text { at - } \alpha(\mathrm{T}) \alpha\left(\mathrm{V}_{6}\right) \\
& \text { zero - } \beta(\mathrm{T}) \alpha\left(\mathrm{E}_{1}\right)\left(\mathrm{E}_{5}\right) \alpha\left(\mathrm{E}_{3}\right) \\
& \text { dark - } \alpha\left(\mathrm{V}_{3}\right) \alpha(\mathrm{T}) \beta\left(\mathrm{E}_{5}\right) \beta\left(\mathrm{V}_{2}\right) \\
& \text { thirty }-\beta\left(\mathrm{E}_{4}\right) \alpha\left(\mathrm{V}_{1}\right) \alpha\left(\mathrm{E}_{2}\right) \beta\left(\mathrm{V}_{5}\right) \beta\left(\mathrm{V}_{6}\right)
\end{aligned}
$$

\section{Horizontal String:}

$$
\begin{aligned}
& \alpha\left(\mathrm{V}_{2}\right) \alpha\left(\mathrm{E}_{1}\right) \alpha\left(\mathrm{E}_{1}\right) \alpha\left(\mathrm{V}_{6}\right)(1,1) \\
& \alpha\left(\mathrm{V}_{6}\right) \beta\left(\mathrm{V}_{5}\right) \alpha\left(\mathrm{E}_{1}\right)(1,1) \beta\left(\mathrm{V}_{5}\right) \alpha\left(\mathrm{E}_{1}\right) \\
& \alpha(\mathrm{T}) \alpha\left(\mathrm{V}_{3}\right)(1,1) \alpha(\mathrm{T}) \alpha\left(\mathrm{V}_{6}\right)(1,1) \beta(\mathrm{T}) \\
& \alpha\left(\mathrm{E}_{1}\right)\left(\mathrm{E}_{5}\right) \alpha\left(\mathrm{E}_{3}\right)(1,1) \alpha\left(\mathrm{V}_{3}\right) \alpha(\mathrm{T}) \\
& \beta\left(\mathrm{E}_{5}\right) \beta\left(\mathrm{V}_{2}\right)(1,1) \beta\left(\mathrm{E}_{4}\right) \alpha\left(\mathrm{V}_{1}\right) \alpha\left(\mathrm{E}_{2}\right) \\
& \beta\left(\mathrm{V}_{5}\right) \beta\left(\mathrm{V}_{6}\right)
\end{aligned}
$$

\section{Matrix Coding:}

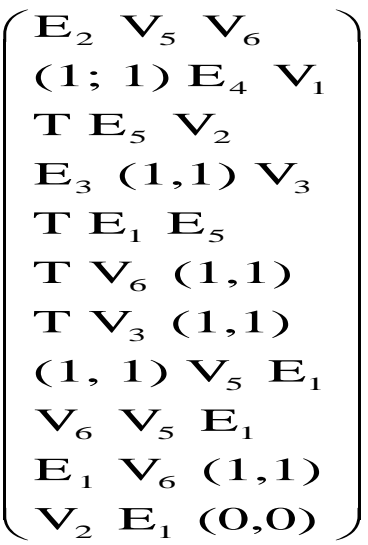

\section{Illustration 3:}

1. Message: The documents are in your purple briefcase intact.

2. Clue: Thrice the special prime and thrice its power. (Thrice the special prime $3 * 2=6$ and thrice its power $2^{3}=8$ )
3. Graph: The two star graph $K_{1,6} \cup K_{1,8}$ :

4. Labeling: The super mean labeling completed for $K_{1,6} \cup K_{1,8}$ is shown in the Fig.3.
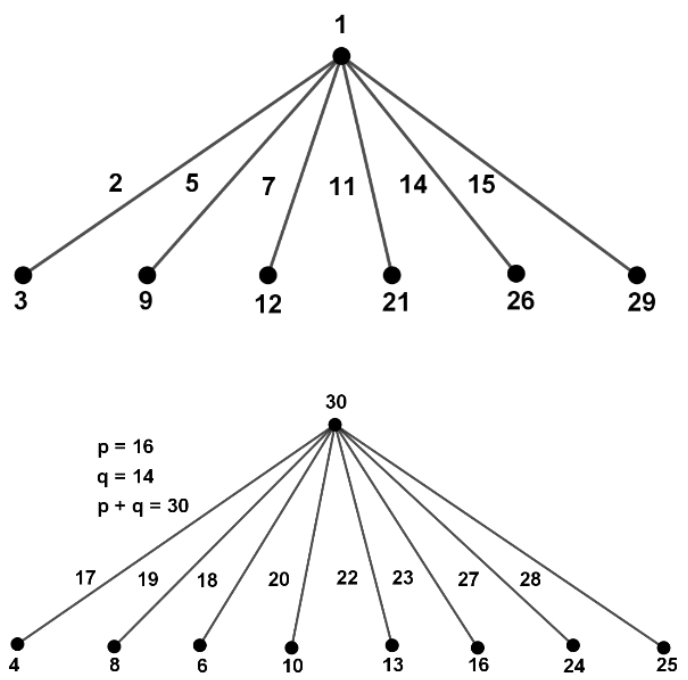

Fig 3: $K_{1,6} \cup K_{1,8}$

\section{Numbering of alphabets: OFEB}

The numbers 1 to 13 and 14 to 26 are allotted to the odd and even positioned alphabets moving forward and backward from $\mathrm{A}$ to $\mathrm{C}$ to $\mathrm{E}$ and $\mathrm{Z}$ to $\mathrm{X}$ to $\mathrm{V}$ and so on, this method is named as OFEB (Odds forward, Evens backward).

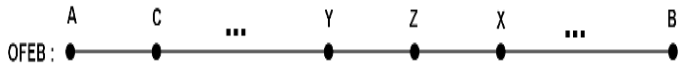

We express the numbering of alphabets in terms of a functions for encoding. For even positioned alphabets the functions is given by,

$g(2 k)=27-k$ for $k=1,2,3 \ldots, 13$.

For odd positioned the function $\mathrm{g}$ us given by

$g(2 k+1)=k+1$ for $k=0,1,2, \ldots, 12$.

For decoding we reverse the process.

5. Coding: (word wise)

The - $\beta\left(\mathrm{E}_{1}\right) \beta\left(\mathrm{E}_{6}\right) \alpha\left(\mathrm{P}_{1}\right)$

documents - $\beta\left(\mathrm{P}_{8}\right) \beta\left(\mathrm{P}_{2}\right) \alpha\left(\mathrm{E}_{1}\right) \alpha\left(\mathrm{E}_{4}\right)$

$\alpha\left(\mathrm{E}_{3}\right) \alpha\left(\mathrm{P}_{1}\right) \beta\left(\mathrm{E}_{4}\right) \beta\left(\mathrm{E}_{1}\right) \beta\left(\mathrm{P}_{4}\right)$

are $-\alpha(\mathrm{T}) \beta\left(\mathrm{E}_{3}\right)\left(\mathrm{P}_{1}\right)$

in $-\alpha\left(\mathrm{E}_{2}\right) \beta\left(\mathrm{E}_{4}\right)$

your - $\beta\left(\mathrm{P}_{5}\right) \beta\left(\mathrm{P}_{2}\right) \alpha\left(\mathrm{E}_{4}\right) \beta\left(\mathrm{E}_{3}\right)$

purple - $\beta\left(\mathrm{E}_{2}\right) \alpha\left(\mathrm{E}_{4}\right) \beta\left(\mathrm{E}_{3}\right) \beta\left(\mathrm{E}_{2}\right)\left(\mathrm{P}_{4}\right) \alpha\left(\mathrm{P}_{1}\right)$

intact - $\alpha\left(\mathrm{E}_{2}\right) \beta\left(\mathrm{E}_{4}\right) \beta\left(\mathrm{E}_{1}\right) \alpha(\mathrm{T})\left(\mathrm{E}_{1}\right) \beta\left(\mathrm{E}_{1}\right)$

briefcase - $\alpha\left(\mathrm{P}_{5}\right) \beta\left(\mathrm{E}_{3}\right) \alpha\left(\mathrm{E}_{2}\right)\left(\mathrm{P}_{1}\right) \beta\left(\mathrm{P}_{7}\right)$

$$
\alpha\left(\mathrm{E}_{1}\right) \alpha(\mathrm{T}) \beta\left(\mathrm{P}_{4}\right) \alpha\left(\mathrm{P}_{1}\right)
$$




\section{Horizontal String:}

$$
\begin{aligned}
& \beta\left(\mathrm{E}_{1}\right) \beta\left(\mathrm{E}_{6}\right) \alpha\left(\mathrm{P}_{1}\right)(1,1) \beta\left(\mathrm{P}_{8}\right) \beta\left(\mathrm{P}_{2}\right) \alpha\left(\mathrm{E}_{1}\right) \alpha\left(\mathrm{E}_{4}\right) \\
& \alpha\left(\mathrm{E}_{3}\right) \alpha\left(\mathrm{P}_{1}\right) \beta\left(\mathrm{E}_{4}\right) \beta\left(\mathrm{E}_{1}\right) \beta\left(\mathrm{P}_{4}\right)(1,1) \alpha(\mathrm{T}) \beta\left(\mathrm{E}_{3}\right)\left(\mathrm{P}_{1}\right) \\
& (1,1) \alpha\left(\mathrm{E}_{2}\right) \beta\left(\mathrm{E}_{4}\right)(1,1) \beta\left(\mathrm{P}_{5}\right) \beta\left(\mathrm{P}_{2}\right) \alpha\left(\mathrm{E}_{4}\right) \beta\left(\mathrm{E}_{3}\right)(1,1) \\
& \beta\left(\mathrm{E}_{2}\right) \alpha\left(\mathrm{E}_{4}\right) \beta\left(\mathrm{E}_{3}\right) \beta\left(\mathrm{E}_{2}\right)\left(\mathrm{P}_{4}\right) \alpha\left(\mathrm{P}_{1}\right)(1,1) \alpha\left(\mathrm{E}_{2}\right) \beta\left(\mathrm{E}_{4}\right) \\
& \beta\left(\mathrm{E}_{1}\right) \alpha(\mathrm{T})\left(\mathrm{E}_{1}\right) \beta\left(\mathrm{E}_{1}\right)(1,1) \alpha\left(\mathrm{P}_{5}\right) \beta\left(\mathrm{E}_{3}\right) \alpha\left(\mathrm{E}_{2}\right)\left(\mathrm{P}_{1}\right) \beta\left(\mathrm{P}_{7}\right) \\
& \alpha\left(\mathrm{E}_{1}\right) \alpha(\mathrm{T}) \beta\left(\mathrm{P}_{4}\right) \alpha\left(\mathrm{P}_{1}\right)
\end{aligned}
$$

For the same shape, graph and sentence different coding pattern is used just for comparison. By using EBOF and the super mean labeling on $K_{1,6} \cup K_{1,8}$ the message encoded.

\section{Illustration 4:}

1. Coding: (word wise)

$$
\begin{aligned}
& \text { The - } \beta\left(\mathrm{P}_{1}\right) \beta\left(\mathrm{P}_{4}\right) \beta\left(\mathrm{P}_{6}\right) \\
& \text { documents }-\alpha\left(\mathrm{P}_{3}\right) \alpha\left(\mathrm{P}_{4}\right) \alpha\left(\mathrm{E}_{6}\right) \beta\left(\mathrm{P}_{7}\right) \\
& \qquad \beta\left(\mathrm{E}_{4}\right) \beta\left(\mathrm{P}_{6}\right) \alpha\left(\mathrm{E}_{3}\right) \beta\left(\mathrm{P}_{1}\right) \beta\left(\mathrm{E}_{6}\right) \\
& \text { are - } \alpha\left(\mathrm{E}_{5}\right) \alpha\left(\mathrm{E}_{2}\right) \beta\left(\mathrm{P}_{6}\right) \\
& \text { in - } \beta\left(\mathrm{E}_{3}\right) \alpha\left(\mathrm{E}_{3}\right) \\
& \text { your - } \alpha\left(\mathrm{P}_{5}\right) \alpha\left(\mathrm{P}_{4}\right) \beta\left(\mathrm{P}_{7}\right) \alpha\left(\mathrm{E}_{2}\right) \\
& \text { purple - } \beta\left(\mathrm{P}_{3}\right) \beta\left(\mathrm{P}_{7}\right) \alpha\left(\mathrm{E}_{2}\right) \beta\left(\mathrm{P}_{3}\right) \alpha\left(\mathrm{E}_{3}\right) \beta\left(\mathrm{P}_{6}\right) \\
& \text { intact - } \beta\left(\mathrm{E}_{3}\right) \alpha\left(\mathrm{E}_{3}\right) \beta\left(\mathrm{P}_{1}\right) \alpha\left(\mathrm{E}_{5}\right) \alpha\left(\mathrm{E}_{6}\right) \beta\left(\mathrm{P}_{1}\right) \\
& \text { briefcase - } \beta\left(\mathrm{P}_{5}\right) \alpha\left(\mathrm{E}_{2}\right) \beta\left(\mathrm{E}_{3}\right) \beta\left(\mathrm{P}_{6}\right) \alpha\left(\mathrm{E}_{4}\right) \\
& \qquad \alpha\left(\mathrm{E}_{6}\right) \alpha\left(\mathrm{E}_{5}\right) \beta\left(\mathrm{E}_{6}\right) \beta\left(\mathrm{P}_{6}\right)
\end{aligned}
$$

\section{Horizontal string:}

$$
\begin{aligned}
& \text { The }-\beta\left(\mathrm{P}_{1}\right) \beta\left(\mathrm{P}_{4}\right) \beta\left(\mathrm{P}_{6}\right)(1,1) \\
& \alpha\left(\mathrm{P}_{3}\right) \alpha\left(\mathrm{P}_{4}\right) \alpha\left(\mathrm{E}_{6}\right) \beta\left(\mathrm{P}_{7}\right)(1,1) \\
& \beta\left(\mathrm{E}_{4}\right) \beta\left(\mathrm{P}_{6}\right) \alpha\left(\mathrm{E}_{3}\right) \beta\left(\mathrm{P}_{1}\right) \beta\left(\mathrm{E}_{6}\right) \\
& \alpha\left(\mathrm{E}_{5}\right) \alpha\left(\mathrm{E}_{2}\right) \beta\left(\mathrm{P}_{6}\right)(1,1) \beta\left(\mathrm{E}_{3}\right) \alpha\left(\mathrm{E}_{3}\right) \\
& (1,1) \alpha\left(\mathrm{P}_{5}\right) \alpha\left(\mathrm{P}_{4}\right) \beta\left(\mathrm{P}_{7}\right) \alpha\left(\mathrm{E}_{2}\right)(1,1) \\
& \beta\left(\mathrm{P}_{3}\right) \beta\left(\mathrm{P}_{7}\right) \alpha\left(\mathrm{E}_{2}\right) \beta\left(\mathrm{P}_{3}\right) \alpha\left(\mathrm{E}_{3}\right) \beta\left(\mathrm{P}_{6}\right) \\
& (1,1) \beta\left(\mathrm{E}_{3}\right) \alpha\left(\mathrm{E}_{3}\right) \beta\left(\mathrm{P}_{1}\right) \alpha\left(\mathrm{E}_{5}\right) \alpha\left(\mathrm{E}_{6}\right) \\
& \beta\left(\mathrm{P}_{1}\right)(1,1) \beta\left(\mathrm{P}_{5}\right) \alpha\left(\mathrm{E}_{2}\right) \beta\left(\mathrm{E}_{3}\right) \beta\left(\mathrm{P}_{6}\right) \\
& \alpha\left(\mathrm{E}_{4}\right) \alpha\left(\mathrm{E}_{6}\right) \alpha\left(\mathrm{E}_{5}\right) \beta\left(\mathrm{E}_{6}\right) \beta\left(\mathrm{P}_{6}\right)(1,1)
\end{aligned}
$$

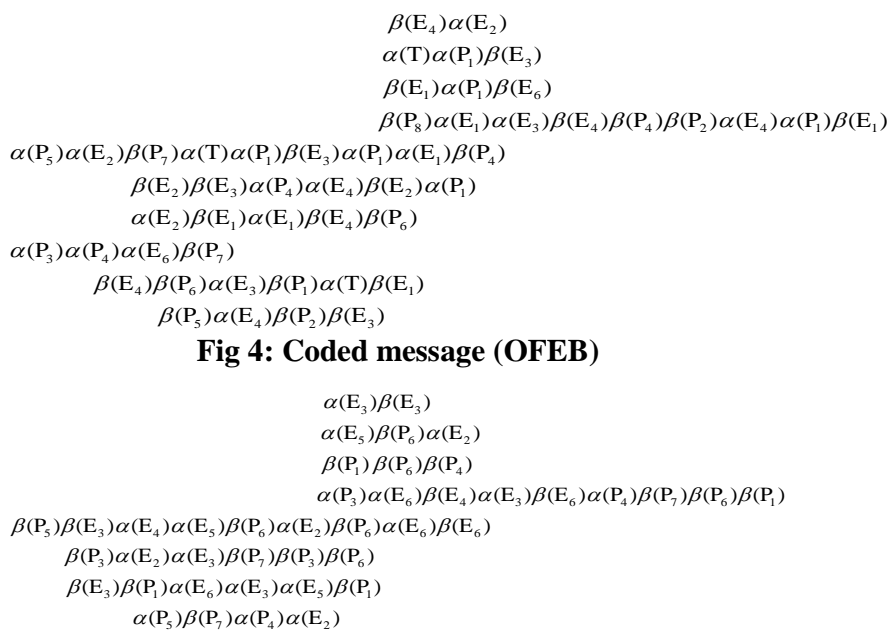

Fig 5: Coded message (EBOF)
For the same sentence the coding are different with respect to the two methods OFEB and EBOF are seen from the above illustrations are given

\section{REFERENCES}

[1] Gross J. L and Yellen J, Hand Book of Graph Theory, (2004), CRC press, Boca Raton.

[2] Gary Chartrand and Ping Zang, Introduction to Graph Theory, Tata MC Graw-Hill Edition ISBN: 0-07061608-6.

[3] Douglas B. West, Introduction to Graph Theory, 2/e Prentice-Hall of India, New Delhi (2003).

[4] P. Jayenthi, D. Ramya and P. Thangavelu, On Super Mean Labeling of Some Graphs, SUT Journal of Mathematics, volume 46(1), (2010), 53 - 66.

[5] P. Jayenthi, D. Ramya and P. Thangavelu, Some Constructions of K - Super Mean Graphs,International Journal of Pure and Applied Mathematics, volume 56(1), (2010), 77 - 86

[6] D. Ramya, R. Ponraj and P. Jayenthi, Super Mean Labeling of Graphs, Ars Combin, volume112, (2013), 65 -72 .

[7] D. Ramya and P. Jayenthi, Super Mean Labeling of Some Classes of Graphs, International Journal of Mathematics Combin, volume 1, (2012), 65 - 72.

[8] R. Vasuki, P. Sugirtha and J. Venkateshwari, Super Mean Labeling of some subdivision graphs, Kragujerac Journal of Mathematics, volume 41 (3), (2017), 179 201.

[9] Alpan Raval, Some Asymptotic Properties of Duplication Graphs, phys Rev. E68 066119, V 68, Issue 6, Dec- 2003

[10] A. Carbone, Duplication of Directed Graphs and Exponential Blow up of proofs, Annals of Pure and Applied logic, volume 100, (1999), 1 - 67.

[11] R. Vasuki and A. Nagarajan, On the Construction of New Classes of Super Mean Graphs, Journal of Discrete Mathematical Sciences and Cryptography, volume 13 (3), (2010), $277-290$

[12] R. Vasuki and A. Nagarajan, Further Results on Super Mean Graphs, Journal of DiscreteMathematical Sciences and Cryptography, volume 14 (2), (2011), 193 - 206.

[13] G. Uma Maheswari, G. Margaret Joan Jebarani and V. Balaji, Coding Through a Two Star and Super Mean Labeling. (Springer - Applied Mathematics and Scientific Computing, volume 2, 2017).

[14] G. Uma Maheswari, G. Margaret Joan Jebarani and V. Balaji, GMJ Coding Through a Three Star and Super Mean Labeling, American International Journal of Research in Science, Technology, Engineering and Mathematics, ISSN print : 2328 - 3491.

[15] G. Uma Maheswari, G. Margaret Joan Jebarani and V. Balaji, Coding Techniques Through Fibonacci Webs, Dierence Cordial Labeling and GMJ Code Method. (Journal of Physics, conference series 1139 (2018) 012077 doi:10:1088/1742-6596/1139/1/012077. 